\title{
1 Two distinct bacterial biofilm components trigger \\ 2 metamorphosis in the colonial hydrozoan Hydractinia echinata
}

3

4 Huijuan Guo, ${ }^{1 \#}$ Maja Rischer, ${ }^{1 \#}$ Martin Westermann, ${ }^{2}$ Christine Beemelmanns ${ }^{1, *}$

51 Leibniz Institute for Natural Product Research and Infection Biology - Hans Knöll Institute,

6 Beutenbergstraße 11a, D-07745 Jena, Germany

$7 \quad 2$ Electron Microscopy Centre, Friedrich Schiller University Jena, Ziegelmühlenweg 1, D-07743

8 Jena, Germany

$9 \quad$ \# contributed equally

10 * Email: Christine.Beemelmanns@hki-jena.de (ORCID 0000-0002-9747-3423)

12 Classification

13 Major: Chemical Sciences

14 Minor: Ecology

15 Keywords

16 Hydractinia, Pseudoalteromonas, metamorphosis, phospholipids, polysaccharides

\section{Author Contributions}

18 Conceptualization: M.R, H.G, M.W., C.B.; Methodology: M.R, H.G, M.W., C.B.; Investigations:

19 M.R, H.G, M.W., C.B.; Resources: M.W., C.B.; Writing - Original Draft: M.R, H.G, C.B.

20 Supervision and Funding Acquisition: M.W., C.B.

21 This PDF file includes:

$22 \quad$ Main Text

$23 \quad$ Figures 1 to 6 


\section{Abstract}

2 Bacterial-induced metamorphosis of larvae is a widespread cross-kingdom communication 3 phenomenon within the marine environment and critical for the persistence of many invertebrate 4 populations. However, the chemical structures of the majority of inducing bacterial signals and the 5 underlying cellular mechanisms remain enigmatic. Hydractinia echinata larvae transform upon 6 detection of bacterial biofilm components into the colonial adult stage. Despite serving as cell 7 biological model system for decades, the inducing bacterial signals remained undiscovered. 8 Using a chemical-ecology driven analysis, we herein identified that specific bacterial 9 (lyso)phospholipids and polysaccharides, naturally present in bacterial biofilms, elicit 10 metamorphosis in Hydractinia larvae. While (lyso)phospholipids (e.g. 16:0LPG/18:1LPE, 16:0 11 LPA/18:1LPE) as single compounds or in combinations induced up to $50 \%$ of all larvae to 12 transform within $48 \mathrm{~h}$, two structurally distinct polysaccharides, the newly identified Rha-Man 13 polysaccharide from Pseudoalteromonas sp. P1-9 and curdlan from Alcaligenes faecalis caused 14 up to $75 \%$ of all larvae to transform within $24 \mathrm{~h}$. We also found combinations of 15 (lyso)phospholipids and curdlan induced the transformation in almost all larvae within $24 \mathrm{~h}$, 16 thereby exceeding the morphogenic activity observed for single compounds and axenic bacterial 17 biofilms. By using fluorescence-labeled bacterial phospholipids, we demonstrated their 18 incorporation into the larval membranes, where interactions with internal signaling cascades 19 could occur. Our results demonstrate that multiple and structurally distinct bacterial-derived metabolites converge to induce high transformation rates of Hydractinia larvae, which might 21 ensure optimal habitat selection despite the general widespread occurrence of both compound 22 classes.

\section{Significance Statement}

25 Bacterial biofilms profoundly influence the recruitment and settlement of marine invertebrates, critical steps for diverse marine processes such as coral reef formation, marine fisheries and the fouling of submerged surfaces. Yet, the complex composition of biofilms often makes it challenging to characterize the individual signals and regulatory mechanisms. Developing tractable model systems to characterize these ancient co-evolved interactions is the key to understand fundamental processes in evolutionary biology. Here, we characterized for the first time two types of bacterial signaling molecules that induce the morphogenic transition and analyzed their abundance and combinatorial activity. This study highlights the crucial role of the converging activity of multiple bacterial signals in development-related cross-kingdom signaling. 


\section{Main Text}

\section{Introduction}

The radical transformation (metamorphosis) of planula larvae into the adult stage is a critical step in the life cycle of many marine species as it confers the propagation and persistence of the population in the marine ecosystem. ${ }^{1}$ For more than 80 years it has been recognized that chemical signals present within marine bacterial biofilms induce or even prevent settlement and metamorphosis in benthic marine larvae, ${ }^{2-4}$ but their identification remains still a challenging task due to low production levels and unestablished model systems. Hence, until today only very few key bacterial signals have been structurally characterized. ${ }^{5-7} \mathrm{~A}$ prime example represents the bacterial product thallusin isolated from Zobellia uliginosa, which induces metamorphosis in the alga Monostroma oxyspermum. ${ }^{8}$ Several members of the Polychaeta class and Cnidaria phylum have also served as model systems for bacterial-induced metamorphosis over decades. ${ }^{9,10}$ In several studies, it was found that bromopyrroles produced by Pseudoalteromonas induce larvae of several coral species to undergo metamorphosis; however induced larvae failed to attach to surfaces when stimulated by bromopyrroles alone indicating that other, yet unidentified, chemical cues might be important for the morphogenic process. ${ }^{11,12}$ Recent biochemical investigations of the bacteria-induced metamorphosis of the marine polychaete Hydroides elegans resulted in the identification of a phage tail-like contractile injection systems (tailocins) in Pseudoalteromonas species that induce settlement and metamorphosis by releasing an effector protein Mif1, which stimulates the P38 and MAPK signaling pathways. ${ }^{13-15}$ However, bacteria not capable of producing theses proteinaceous injection systems were also found to induce the transformation releasing additional, yet structurally not defined morphogens. ${ }^{16,17}$ In the 1970 s, Leitz and Wagner reported that a lipid-like molecule of Pseudoalteromonas espejiana (original name: Alteromonas espejiana) induces larvae transformation in Hydractinia echinata, an early branching metazoan lineage dating back more than 500 million years. ${ }^{18,19}$ But despite intensive studies, the bacterial signals causing Hydractinia larvae to metamorphose have remained elusive. Instead, metamorphosis of Hydractinia was artificially induced using high salt concentrations ( $\mathrm{CsCl}$ ) allowing seminal studies on migratory stem cells, allorecognition (self-recognition), the canonical Wnt-signalling system, and the development of muscles and nervous systems. ${ }^{20,21}$ However, it was noted from early on that artificial induction caused phenotypical and developmental differences in Hydractinia development compared to bacterial induction. ${ }^{22}$

The long-standing unsolved question about the structures of bacterial signals and the apparent morphological differences in larvae development between artificial and natural induction attracted our interest. Thus, we set out to solve the structures of the bacterial signals that induce metamorphosis in Hydractinia, which would allow us to shed light on the biochemistry underlying this ancient prokaryote-eukaryote signaling mechanisms. ${ }^{23}$ 


\section{Results}

2 Bioassay-guided identification of bacterial signals

3 To investigate which co-occurring bacteria induce metamorphosis in $\mathrm{H}$. echinata (hereafter

4 Hydractinia) we isolated morphological distinct co-occurring bacterial species from the surface of 5 a healthy and freshly collected Hydractinia colony. ${ }^{24}$ For a mono-species biofilm-based 6 metamorphosis assay, we selected 29 representative bacterial isolates, including seven genome7 sequenced Hydractinia-associated strains, one coral associated strain Pseudoalteromonas sp. 8 PS5, ${ }^{11,12}$ and eight bacterial type strains obtained from culture collections. Similar to previous 9 observations, we observed the inconsistent timing of metamorphosis using biofilms compared to 10 the artificial control ( $>6 \mathrm{mM} \mathrm{CsCl}$ final concentration), presumably due the inhomogeneous 11 nature of biofilms and spatial concentrations differences of the yet unidentified inducing signals in 12 bacterial biofilms. To enable a comparative analysis of the inducing activity, we adopted the 13 established stage-chart of morphological appearances by Leitz and coworkers to describe and 14 calculate biofilm-induced rates of transformation (Figure S1) ${ }^{18,19}$ In short, the percentage of 15 larvae settlement includes only counts of larvae in morphological stages 9-11, and the 16 percentage of complete metamorphosis includes only counts of larvae in morphological stages 12-14. Based on these assessments, transformation rates are given as averaged percentage ranges in $10 \%$ step ranges, which are calculated from replicates of experiments performed with different larvae batches (different spawning events to ensure reproducibility of results). As depicted in Figure 1, our bioassays resulted in the identification of five Hydractinia-associated bacterial strains that caused up to $60 \%$ of all larvae to undergo complete transformation to the primary polyp. Most notably, three strains (P1-9, P6-7, P1-29) rapidly induced the transformation reaching the morphological stages 13-14 within $24 \mathrm{~h}$. Additional five strains were found to induce the transformation to stages 9-11 within the first $24 \mathrm{~h}$, but subsequent development into the primary polyp was only observed within $48 \mathrm{~h}$. In addition, we observed that up to eleven strains induced the transformation of larvae to morphogenic stage 9-11. However, neither of those strains induced the full transformation to the primary polyp leading eventually to the death of the transforming organism. In addition, six strains were found to be non-inducing and four strains caused the death of up to $100 \%$ of all larvae within $24 \mathrm{~h}$. The results of this study suggested firstly that more than one structurally distinct bacterial signal might induce the transition and secondly that the mode of action might differ depending on the structure of secreted molecule. Amongst all tested strains, Pseudoalteromonas sp. P1-9 (referred from now on as P1-9) was found to induce the most robust morphogenic response and thus was selected for further chemical analysis

34 (Figure 2). ${ }^{25-27}$ 


\section{A}
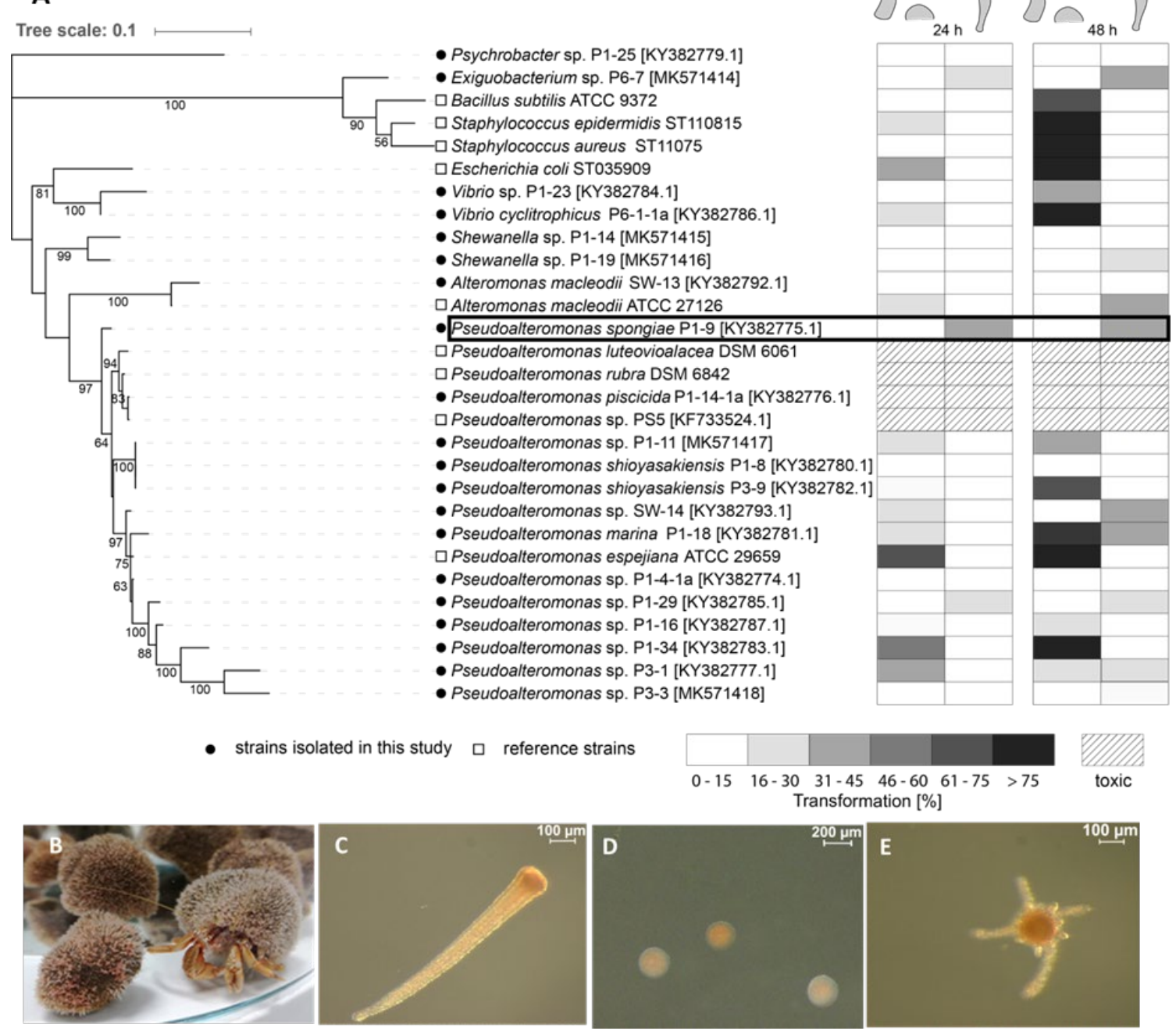

Figure 1. Assessment of morphogenic activity of selected bacterial strains. A) Left: phylogenetic tree based on 16S rRNA gene sequences of 29 tested bacterial strains. Best DNA model was generated and the robustness of interfered tree topologies was evaluated after 1000 bootstraps (> 50\% are shown). Right: Heatmap depicts transformation percentage (stage 9-11 and 12-14) of $H$. echinata larvae counted after 24 and $48 \mathrm{~h}$ (negative control: ASW; positive control: $\mathrm{CsCl}$ ). Transformation rates are given as averaged percentage ranges in 10\% step ranges, which are calculated from replicates of experiments performed with different larvae batches. B) Hydractinia echinata colonizing the shell inhabited by a hermit crab (Pagurus sp.). C-E) Microscopic image of C) planula larva; D) initiation of morphogenic transformation by disc formation (morphological stage 9-10); E) formation of primary polyp (morphological stage 14).

To test if the morphogenic cue of P1-9 is a secreted and/or a diffusible small metabolite, we first tested solid-phase extracts (C18 cartridges) derived from liquid and plate cultures of P1-9. However, none of the tested solid-phase extracts showed morphogenic activities compared to living bacterial biofilms (positive control) (entry 3, Figure 2). We then tested if the signal is a 
1 secreted high-molecular weight (HMW) biomolecule (e.g. protein, exopolysaccharides (EPS))

2 and/or part of the bacterial membranes.

3 Size exclusion based separation of culture supernatants and cell membrane fragments resulted in

4 the isolation of a HMW fraction ( $>30 \mathrm{kDa}$ ) that showed remarkably high morphogenic activity in a

5 dose-response manner (entry 5). In contrast, low-molecular weight fractions $(<5 \mathrm{kDa})$ showed

6 only moderate to very low morphogenic activities (entry 6).

7

\begin{tabular}{|c|c|c|c|}
\hline Entry & Substrate & 37 & Characteristics \\
\hline 1 & Sea water control (ASW) & - & Negative control \\
\hline 2 & $\mathrm{CsCl}(6 \mathrm{mM})$ & ++ & Positive control \\
\hline 3 & $\begin{array}{l}\text { Bacterial cells from plate and } \\
\text { liquid culture }\end{array}$ & ++ & $\begin{array}{l}\text { Part of cells or } \\
\text { extracellular matrix }\end{array}$ \\
\hline 4 & $\begin{array}{l}\text { Solid phase }(\mathrm{C}-18) \text { extracts of } \\
\text { culture supernatants }\end{array}$ & - & $\begin{array}{l}\text { No secreted small } \\
\text { molecule }\end{array}$ \\
\hline 5 & $\begin{array}{l}\text { Size exclusion filtration of } \\
\text { culture supernatants (> } 30 \mathrm{DA})\end{array}$ & ++ & $\begin{array}{l}\text { Part of membrane or } \\
\text { extracellular matrix }\end{array}$ \\
\hline 6 & $\begin{array}{l}\text { Size exclusion filtration of } \\
\text { culture supernatants }(<5 \mathrm{kDA})\end{array}$ & + & $\begin{array}{l}\text { Non secreted small } \\
\text { molecule }\end{array}$ \\
\hline 7 & $\begin{array}{l}\text { Outer membrane vesicles } \\
\text { and/or membrane layers }\end{array}$ & ++ & $\begin{array}{l}\text { Bound to cells or } \\
\text { extracellular matrix }\end{array}$ \\
\hline 8 & EPS Isolation & ++ & $\begin{array}{l}\text { Extracellular } \\
\text { polysaccharides }\end{array}$ \\
\hline & \multicolumn{3}{|c|}{ Treatment of bacterialmembrane fraction } \\
\hline 9 & DNasel & ++ & No DNA \\
\hline 10 & RNase A & ++ & No RNA \\
\hline 11 & Proteinase $\mathrm{K}$ & ++ & No proteins \\
\hline 12 & Heating at $90^{\circ} \mathrm{C}$ & ++ & Heat resistant \\
\hline 13 & $6 \mathrm{M} \mathrm{NaOH}, 30^{\circ} \mathrm{C}, 12 \mathrm{~h}$ & ++ & Base stable - soluble \\
\hline 14 & $6 \mathrm{M} \mathrm{HCl}, 30^{\circ} \mathrm{C}, 12 \mathrm{~h}$ & ++ & Partial acid stable \\
\hline 15 & $6 \mathrm{M} \mathrm{HCl}, 60-90^{\circ} \mathrm{C}, 12 \mathrm{~h}$ & $\overline{-}$ & Hydrolysis \\
\hline & Extraction of cell membrane & & \\
\hline 15 & $\mathrm{H}_{2} \mathrm{O}$ & + & Water soluble \\
\hline 16 & $\mathrm{CHCl}_{3}$ or cyclohexane & + & \multirow{2}{*}{$\begin{array}{l}\text { small molecule-part } \\
\text { of cell membrane }\end{array}$} \\
\hline 17 & Ethylacetate & ++ & \\
\hline 17 & $\mathrm{MeOH} / \mathrm{CHCl}_{3}$ & ++ & Polar lipids \\
\hline
\end{tabular}

Figure 2. Morphogenesis assay of biosamples derived from P1-9. Transformation rates to morphological stages 12-14 were calculated from replicates of experiments performed with different larvae batches after 48 h (- (no induction); + (< 40\%; low induction); ++ $>40 \%$ high induction).

Enrichment of outer membrane vesicles and mini cells from culture supernatants by ultracentrifugation induced high transformation rates already within the first $24 \mathrm{~h}$ resulting in fully transformed larvae after $48 \mathrm{~h}$ (entry 7 ). Thus, we reasoned that the morphogenic cues might be part of the outer cell membrane and/or of high molecular weight. To determine the stability of the morphogens and to optimize purification methods, we subjected the active HMW fractions (> 30 
$1 \mathrm{kDa}$ ) to enzymatic and physical treatments and tested the morphogenic response after treatment.

2 As depicted in Figure 2, activity was completely retained when samples were treated with

3 digestive enzymes such as DNase, RNase, or proteinase $\mathrm{K}$, or even when heated to $96{ }^{\circ} \mathrm{C}$ for

$410 \mathrm{~min}$ (entries 9-12). Treatment of the active fraction with aqueous $6 \mathrm{M} \mathrm{NaOH}$ or $6 \mathrm{M} \mathrm{HCl}(12 \mathrm{~h}$,

$530^{\circ} \mathrm{C}$ ) partially solubilized the active morphogen (entry 13,14 ), and activity of both, soluble

6 fraction and residue, was mostly retained after neutralization. However, treatment with $6 \mathrm{M} \mathrm{HCl}$ at

7 higher temperatures $\left(>60^{\circ} \mathrm{C}\right)$ gradually abolished the morphogenic activity of the sample. Based

8 on these tests, we deduced that the morphogen(s) was neither a sensitive protein, nucleic acid

9 nor an instable secreted metabolite. Morphogens were also extractable from the bacterial

10 membranes and methanolic extracts showed indeed the highest morphogenic activity (entry 17,

11 18), while aqueous extracts retained only moderate activity (entry 15). Taken together, our results

12 indicated that presumably two different bacterial morphogens are produced by P1-9, which are

13 stable and extractable and likely localized within or at the bacterial outer membrane.

\section{Analysis of morphogenic phospholipids}

In a next step, we sought to characterize the morphogenic cues and applied a bioassay-guided reverse-phase column chromatography (HPLC) purification protocol. The resulting active HPLC fractions were analyzed by high-resolution tandem mass spectrometry (HR-MS ${ }^{2}$ ) and Global Natural Product Social Molecular Networking (GNPS) ${ }^{28}$ analysis revealing the dominant presence of different phosphatidylglycerol (PG) and phosphatidylethanolamine (PE) species and the respective lyso derivatives (LPG, LPE). Due to inherent difficulties associated with the purification of structurally closely related phospholipids, we purchased eleven commercial derivatives that matched the proposed derivatives to compare the LC-HRMS ${ }^{2}$ pattern (Figure S12-S17), as well as ${ }^{1} \mathrm{H}$ and ${ }^{13} \mathrm{C}$ nuclear magnetic resonance (NMR) spectra (chemical shifts and coupling constants) (S28-S52).

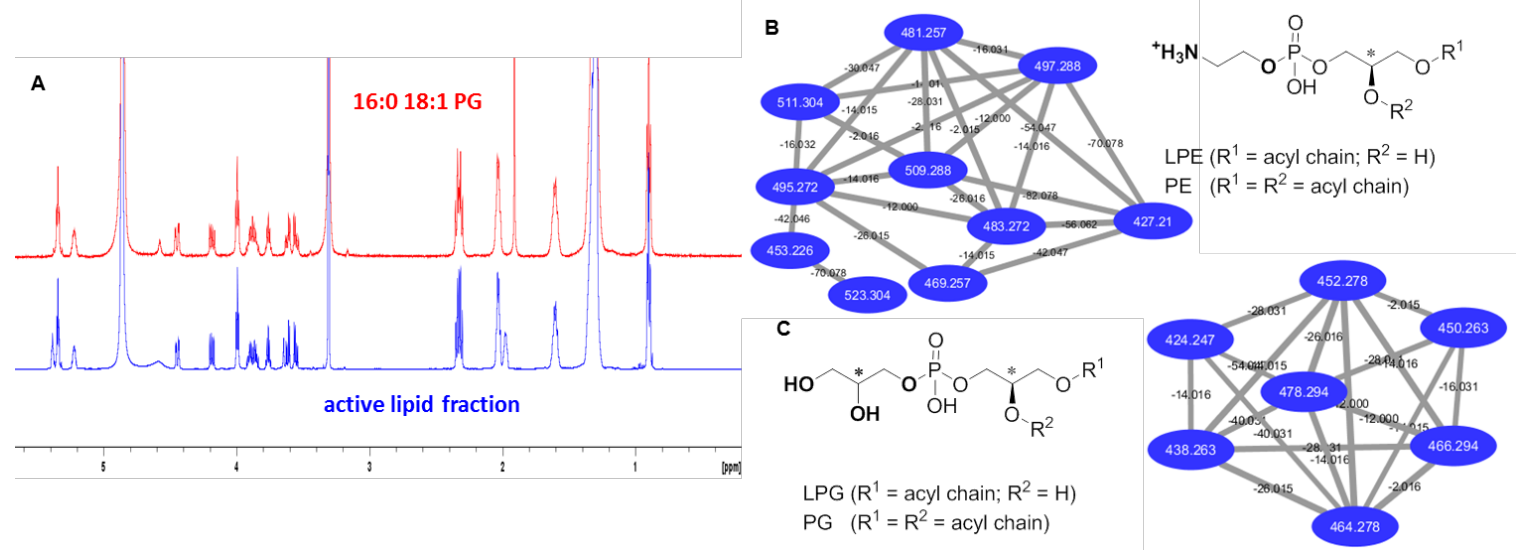

Figure 3. A) ${ }^{1} \mathrm{H}-\mathrm{NMR}$ spectra of commercial 16:0-18:1 PG (red) and morphogenic PG/LPG enriched fraction (blue). B-C) LC-HRMS ${ }^{2}$ based GNPS analyses of purified lipid fraction showing the B) LPE and C) LPG $M S^{2}$-cluster. 
1 We then confirmed the morphogenic activity of commercial phospholipids including two 2 derivatives containing fluorescence labels (Figure 4) using 25 and $50 \mu \mathrm{M}$ as final lipid

3 concentrations (based on preliminary dose-response tests using lipid extracts and commercial 4 16:0 LPG (Figure S15)). Here, it is noteworthy that phospholipid concentrations of single lipids or 5 combination thereof exceeding $50 \mu \mathrm{M}$ occasionally caused the lysis of the organism (Figure 4).

6 Transformation rates were determined after 24 and $48 \mathrm{~h}$, respectively; however statistical 7 analyses of assay data was not performed at this stage as induction by phospholipids resulted in 8 a non-synchronized behavior of larval transformation, similar to the observation made in axenic 9 biofilm assays. However, none of the tested single phospholipids recapitulated the full activity 10 observed for enriched phospholipid fractions derived from P1-9, but derivatives 16:0 LPG, 18:0 $11 \mathrm{PE}$, and 16:0 (lyso)phosphatidic acid (16:0 LPA and 16:0 PA) repeatedly induced metamorphosis 12 in moderate to good rates (20-40\%).

13 At this stage we questioned if the low solubility of (lyso)phospholipids might prevent the uptake 14 and perception by Hydractinia. Thus, we treated competent larvae with nitrobenzoxadiazole 15 (NBD)-labeled (phospho)lipids (18:1-12:0 NBD PG, 18:1-12:0 NBD PE or 12-NBD stearate 16 (Table S3), $25 \mathrm{nmol} / \mathrm{mL}$ ) and found that all lipids were incorporated into the larvae membrane 17 within five hours and both phospholipid derivatives. While 12-NBD stearate did not induce 18 transformation to the primary polyp, 18:1-12:0 NBD PG and PE were found similarly active as 19 unmodified phospholipids (Figure 4). Here, it was noted that during metamorphosis the 20 fluorescence signal continuously decreased over time, presumably due to internalization and 21 decomposition of phospholipids during transformation processes (Figure 4, Table S3). Thus, it 22 was concluded at this stage that induction of metamorphosis by bacterial-derived phospholipids 23 presumably occurs by passive uptake of lipids into the larvae membrane, is strongly structure24 and concentration dependent and presumably orchestrated by Hydractinia-internal feedback25 loops.

26 Phospholipids (PL) and lysophospholipids (lyso-PLs, LPLs) are ubiquitous components of 27 bacterial cell walls and determine e.g. cell integrity and morphology as well as pathogen-host 28 interactions. ${ }^{29,30}$ However, little details are known about their possible signaling functions in 29 bacteria. ${ }^{31}$ As bacterial membranes and outer membrane vesicles (OMVs) are composed of 30 species-specific mixtures of (lyso)phospholipids, we hypothesized that the natural phospholipid 31 compositions of cells and bacterial biofilms will dictate the morphogenic activity and that additive 32 or even synergistic effects may play an important role in the induction process. 
A
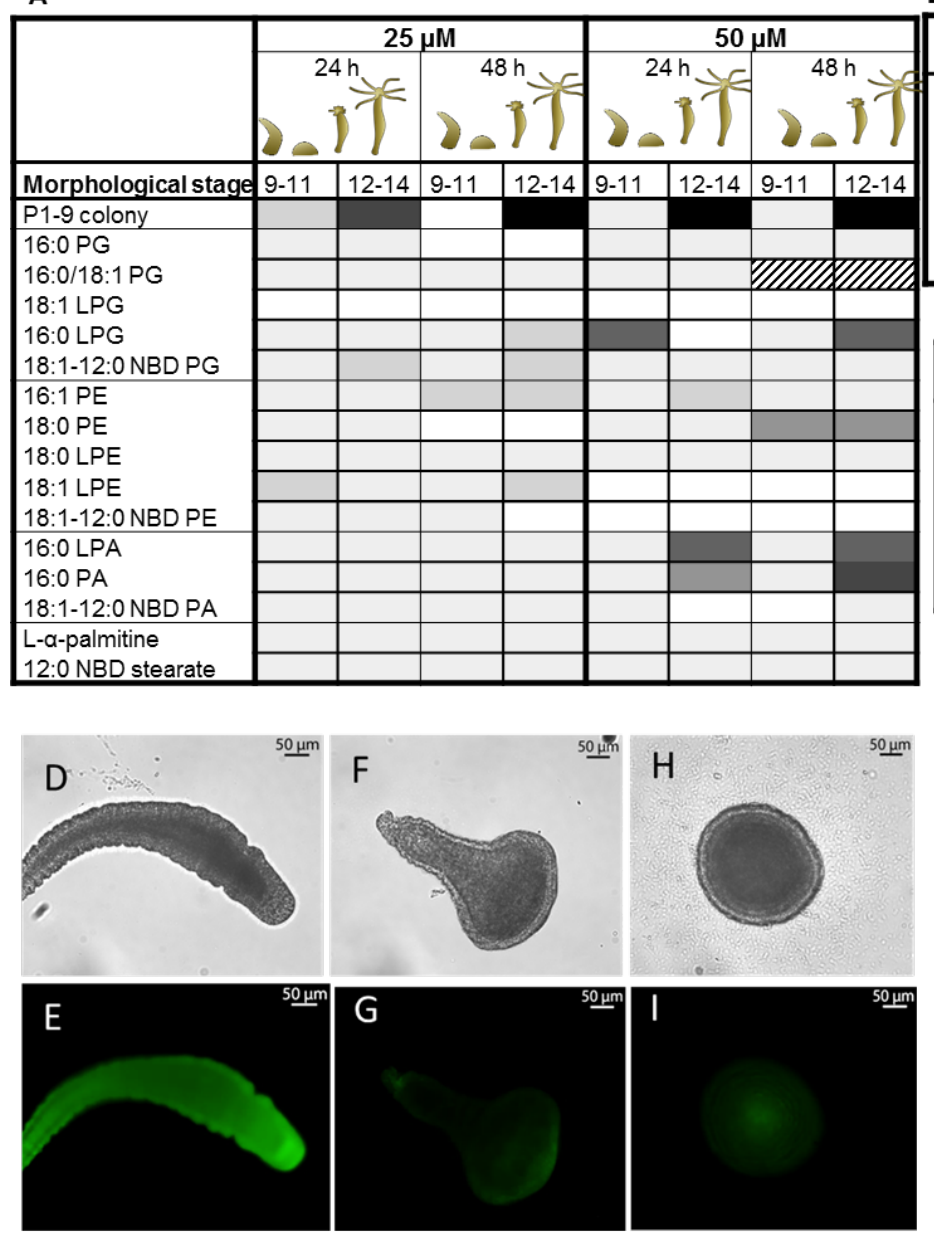

F

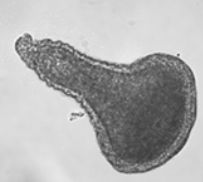

G

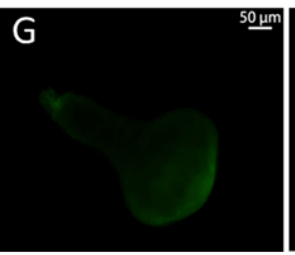

H

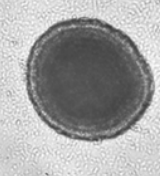

I

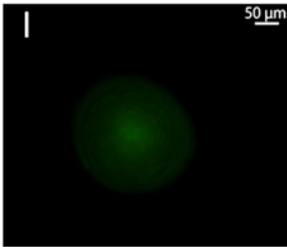

B
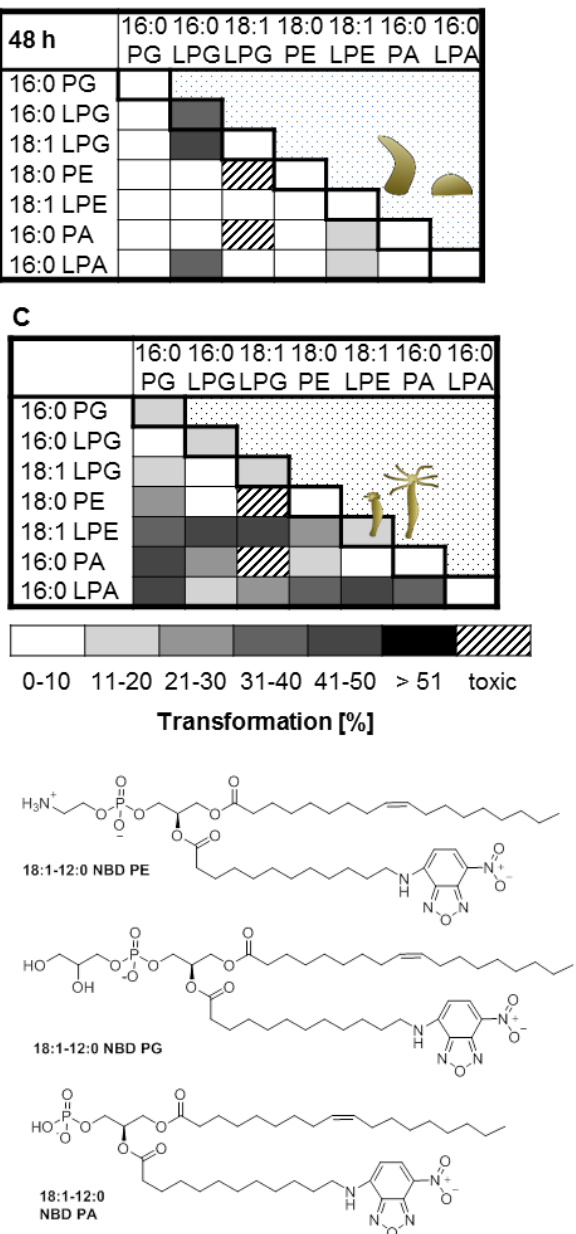

Figure 4. Metamorphosis inducing activity of commercial phospholipids. Transformation rates are given as averaged percentage ranges in $10 \%$ step (calculated from replicates of experiments performed with different larvae batches). Negative control: ASW; positive control: CsCl. A) Bioactivity test were performed using 25 and $50 \mu \mathrm{M}$ final lipid concentrations. Transformation rates to morphological stage 9-11 and stage 12-14 were determined after 24 and $48 \mathrm{~h}$. B-C) Activity tests of phospholipid combinations $(25 \mu \mathrm{M}$ of each lipid in a 1:1 combination with a final lipid concentration of $50 \mu \mathrm{M}$ ). Transformation rates to morphological stages 9-11 (B) and stages 12-14 (C) were determined after $48 \mathrm{~h}$. D-K) Fluorescence labeling images of larvae treated with (D, E) 18:1-12:0-NBD PE; ( $F, G)$ 18:1-12:0-NBD PA; (H-I) 18:1-12:0 NBD PG undergoing metamorphosis (fluorescence imaging with emission wavelength at $527 \mathrm{~nm}$ ).

Thus, we tested enriched phospholipid extracts $(125 \mu \mathrm{g} / \mathrm{mL}$ lipid extract) of 16 different Hydractinia-associated bacterial strains including strains that were found inactive in biofilm assays for morphogenic activity (Figure S13). Indeed, extracts of several different strains (P1-23, SW13, P1-9, P. rubra, P3-9, P1-4-1a, P1-16) induced the transformation to the primary polyp (stage 12-14) in moderate to good rates within $48 \mathrm{~h}$, in part exceeding the results of our previous biofilm experiments (Figure 1, S13). In contrast, lipid extracts of four strains caused cell lysis and/or abnormal transformations at the tested concentration, presumably due to the presence of overall toxic phospholipid concentrations or known cytotoxic (hydrophobic) natural products 
1 (violacein and/or poly-brominated pyrrole derivatives) naturally present within the bacterial cells

2 and membranes of the producing organisms. We also analyzed the phospholipid composition of

3 cell extracts by comparative high resolution tandem mass spectrometry $\left(\mathrm{HRMS}^{2}\right)$ and found a

4 species-specific abundance of phospholipids that only in part resembled the composition of our

5 model strain P1-9. Despite the absence of detectable amounts of (L)PA derivatives, we

6 hypothesized that the combination of several weakly active (L)PE and (L)PG might be

7 responsible for the observed clear activity. To corroborate these findings, we then conducted

8 combination assays of a defined subset of phospholipids (50 $\mu \mathrm{M}$ final concentrations). Indeed,

9 several tested phospholipid combinations showed additive or even synergistic tendencies to

10 induce metamorphosis within $48 \mathrm{~h}$, in particular the combinations of 18:1 LPE/16:0 LPG, 18:1

11 LPE/18:1 LPG, 16:0 PA/16:0 PG, 16:0 LPA/16:0 LPG and 16:0 LPA/18:1 LPE (Figure 4). At this

12 stage we concluded that specific (lyso) phospholipids and combinations thereof, known to be

13 present in bacterial cell membranes and OMVs, are in part responsible for metamorphosis of

14 Hydractinia larvae.

\section{Analysis of morphogenic polysaccharide}

As depicted in Figure 2, our bioassay-guided analysis indicated the presence of a second type of morphogenic compound of high-molecular weight (HMW, $>10 \mathrm{kDa}$ in size) and naturally present within aqueous extracts of Pseudoalteromonas P1-9 biofilms (Figure S9). Thus, we enriched for the secreted bioactive compound by size-exclusion filtration and analyzed the most active fractions by ${ }^{1} \mathrm{H}$ NMR, which revealed a complex mixture of yet unknown polysaccharides (Figure S21). Further purification (Sephadex G25, eluted with $0.1 \% \mathrm{NH}_{4} \mathrm{OH}$ ) and semipreparative HPLC (Shodex) and NMR and HRMS analysis of the most active fraction (> induction of $20 \%$ ) revealed the presence of a polysaccharide consisting of repeating $-\left(1^{\prime} \rightarrow 4\right)-\alpha-L-R h a-$ $\left(1 \rightarrow 3^{\prime}\right)$-D-Man- units (> $10 \mathrm{kDa}$, Figure 5, Figure S19-S27). The rhamnose/mannose composition was confirmed by acid hydrolysis using $6 \mathrm{M} \mathrm{HCl}$, followed by TMS derivatization and GC-MS analysis and comparison with commercial standards (Figure S18). The purified polysaccharide, from now on named Rha-Man, showed a clear dose-dependent morphogenic induction of up to $80 \%$ transformation within $48 \mathrm{~h}(>150 \mu \mathrm{g} / \mathrm{mL}$, Figure S19). Partial acid hydrolysis resulted in loss of morphogenic activity. At this stage, we also tested rhamnose and glucose monomers at different concentrations, but no induction was observed. Comparative NMR-analysis of bioactive size-exclusion fractions revealed that Rha-Man was only a minor component of the highly bioactive polysaccharide fraction, which pointed towards additional not-yet structurally characterized P1-9-specific exopolysaccharides (EPS) derivatives with morphogenic properties (Figure S21). 


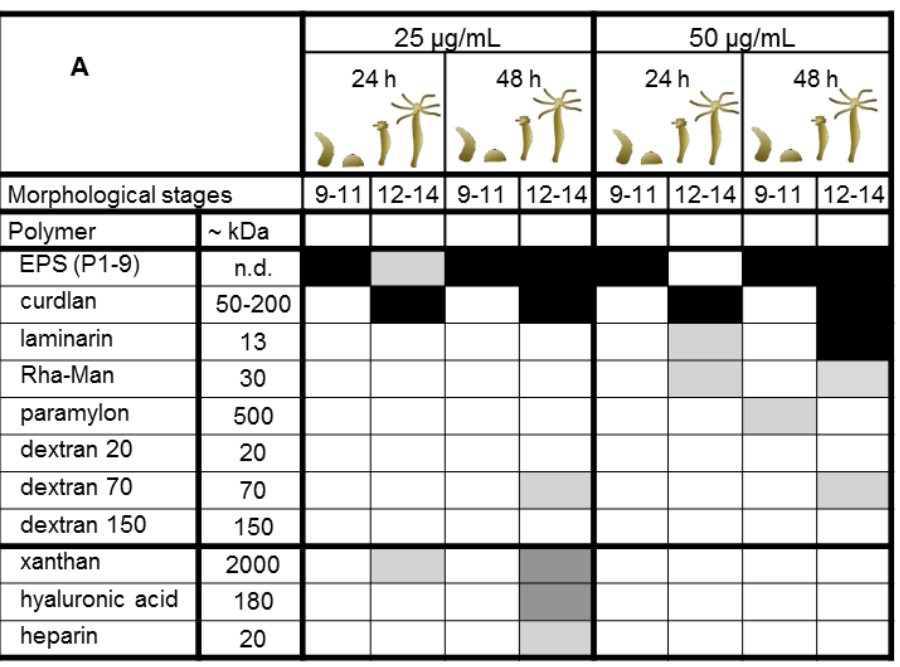

B

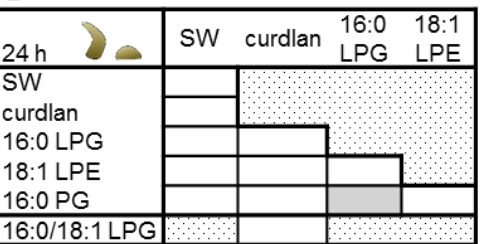

C
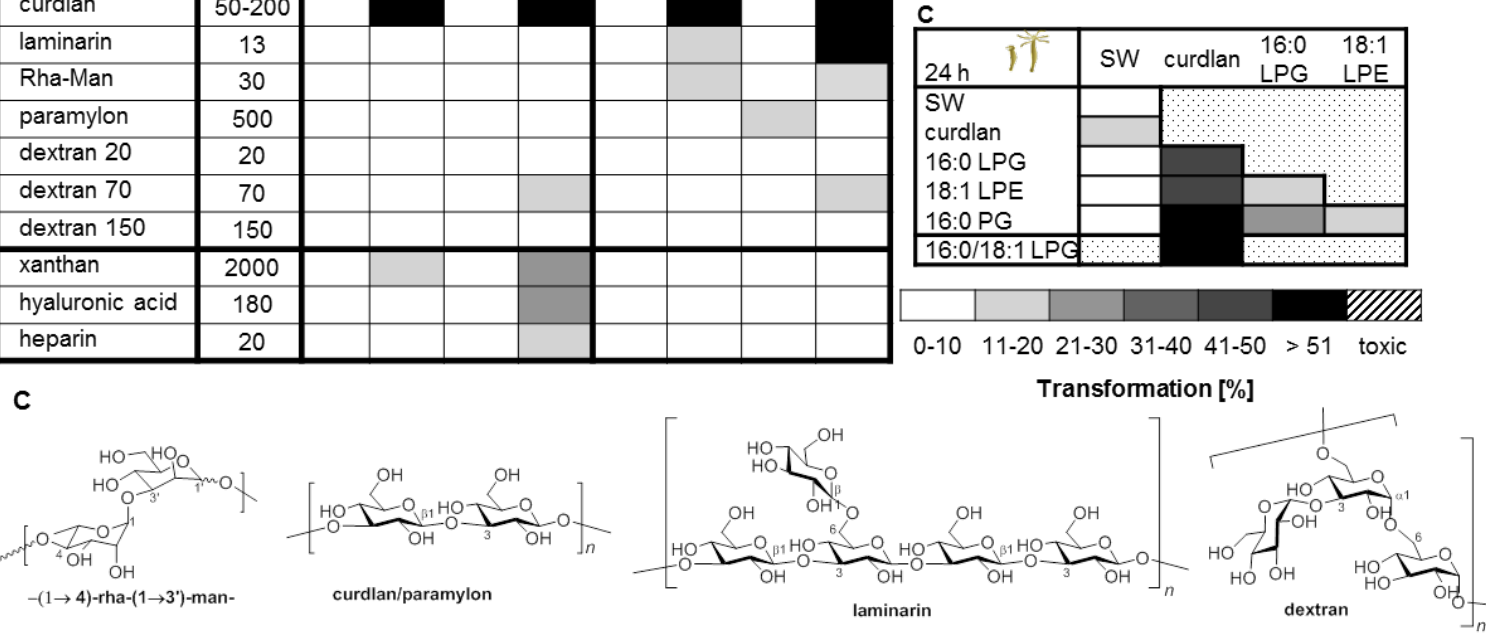

Figure 5. Metamorphosis inducing activity of enriched and purified polysaccharides from P1-9 and commercial polysaccharides. Transformation rates are given as averaged percentage ranges in $10 \%$ step (calculated from replicates of experiments performed with different larvae batches). Negative control: ASW; positive control: $\mathrm{CsCl}$. A) Bioactivity test were performed using (25 $\mu \mathrm{g} / \mathrm{mL}$ ) and transformation rates to morphological stage 9-11 and stage 12-14 were determined after 24 and $48 \mathrm{~h}$, respectively. B-C) Bioactivity tests of phospholipids (10 $\mu \mathrm{g}$ per lipid) and curdlan combinations and $15 \mu \mathrm{g}$ curdlan) were assessed after $24 \mathrm{~h}$. D) Structures of repeating units of morphogenic polysaccharides.

Due to the inherent difficulties associated with the structural characterization of EPS in general and from P1-9 in particular, we decided to examine structure-function relations using structurally defined and more widely distributed bacterial polysaccharides (charged and non-charged). Intriguingly, curdlan, a well-known polysaccharide (50-200 kDa) with ß-1,3-glycosidic linkage and produced by the Gram-negative bacterium Alcaligenes faecalis, induced at significant lower dosage $(25 \mu \mathrm{g} / \mathrm{mL})$ the transformation to the primary polyp within $24 \mathrm{~h}$ (Figure 5). In contrast, paramylon, the $500 \mathrm{kDa}$ derivative of curdlan, which differs in its average length and threedimensional structure, ${ }^{32}$ induced the transformation only in moderate to low percentage. Other EPS derivatives, in particular charged EPS (hyaluronic acid and heparin), induced only in very low rates or were even toxic to larvae (Figure 5); secondary effects due to acidic/ionic properties cannot be excluded for these derivatives. At this step, we concluded that Hydractinia larvae respond in a dose-dependent fashion to the presence of two structurally distinct EPS derivatives and fully developed primary polyp (> 50\% transformation rates) within 24-48 h. 
1 We then tested if phospholipids and the identified polysaccharides induced morphogenesis in an 2 additive or synergistic manner as both compound types co-occur within the bacterial biofilm.

3 Thus, we tested combinations of moderately active lysophospholipids, 16:0 LPG and 18:1 LPE, 4 as well as curdlan using lower concentration of individual compounds (10 and $15 \mu \mathrm{g} / \mathrm{mL}$, 5 respectively). As expected, curdlan showed dose-dependent activity and induced transformation 6 to the primary polyp at lower rates compared to 25 and $50 \mu \mathrm{g} / \mathrm{mL}$. Intriguingly, combinations of 7 curdlan with either 16:0 LPG, or 18:1 LPE, or both derivatives resulted in almost $100 \%$ 8 transformation rates within $24 \mathrm{~h}$, which indicated towards synergistic (more than additive) 9 activities. In addition, we also observed that larvae triggered by the combination of natural 10 inducers developed more rapidly and cleanly into a fully functional primary polyp compared to 11 artificial induction.
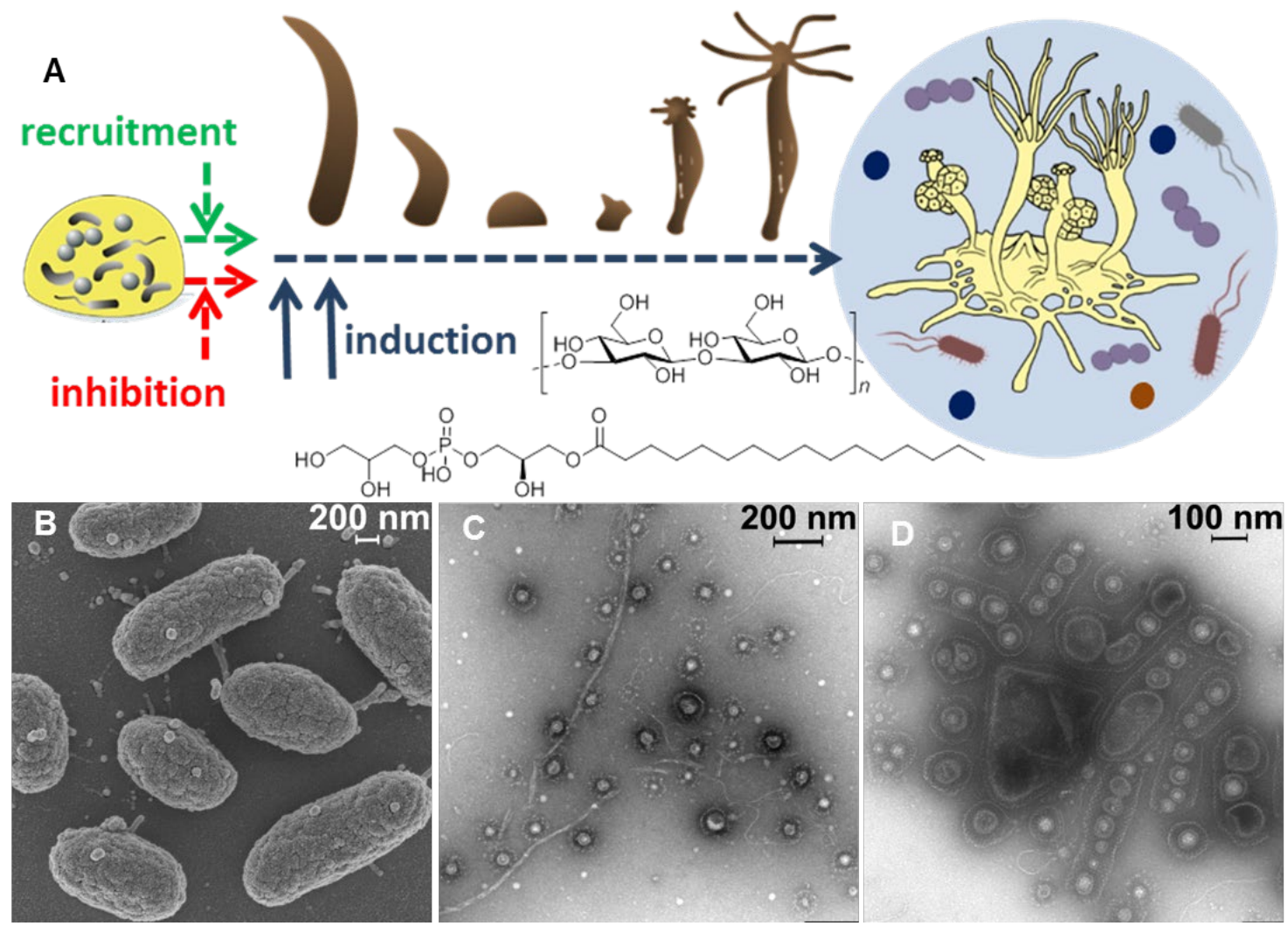

Figure 6. Specific phospholipids, naturally present in bacterial cells and outer membrane vesicles, and exopolysaccharides induce metamorphosis in $H$. echinata. A) Components of bacterial biofilms recruit and induce metamorphosis of competent $H$. echinata larvae; or prevent the transformation by killing larvae by secretion of toxic compounds. B) Scanning electron microscopy of single cells of P1-9 obtained from a three day old liquid culture. C-D) Negative contrast electron microscopic image of vesicles coated with S-layer like matrix and string-shaped biopolymers isolated from a three day old liquid culture of P1-9 (C) and agar plate derived P1-9 biofilm (D). 
1 The lipophilic nature of phospholipids and insolubility of polysaccharides raised the question of

2 how the bacterial signaling molecules are sensed and perceived by Hydractinia. In recent years

3 evidence has been mounting that extracellular (or outer membrane) vesicles (OMVs) represent a

4 highly conserved feature and potential mechanisms/vehicles of lipophilic signaling molecules that

5 orchestrate the interaction between bacteria and marine eukaryotes. ${ }^{33-35}$ To assess if P1-9

6 produces OMVs, we performed electron microscopy (TEM) imaging of shaking and static cell

7 cultures. Examinations of TEM images revealed entire cells and cells proliferating what appears

8 to be outer membrane vesicles (100-300 nm, Figure 6). Interestingly, (cryo)TEM imaging of

9 aqueous extracts of P1-9 biofilms and liquid culture revealed a high abundance of numerous

10 extracellular vesicles of different sizes and forms (Figure 6A,C,D) as well as high abundances of

11 biopolymer fibers (Figure 6B,C), which were positively tested for high morphogenic induction

12 (Figure 2). Thus, it can be concluded at this stage that morphogens are naturally present within

13 the biofilm matrix and are likely detected in form of OMVs and/or bacterial cell envelops.

\section{Discussion}

16 We successfully identified two types of bacterial morphogenic cues, a subset of (lyso)phospholipids and two bacterial polysaccharides (Rha-Man, curdlan) from gram-negative bacteria that induce the morphogenic transformation of Hydractinia planula larva into the primary polyp. Detailed structure-activity studies of both compound types revealed a strong concentration and structure-dependency of the morphogenic response. In case of phospholipids, 18:0 PE, 16:0 LPG and 16:0 LPA/PA showed the highest induction levels as single compounds and in combination with other lipids, while other phospholipid combinations were found to be inactive or even toxic to the larvae. Subsequent bioassays of phospholipid-rich bacterial extracts further indicated that the overall compositions dictates the final morphogenic response and effects could be overruled by the presence of toxic metabolites leading to abnormal or incomplete transformation or even death of the larvae. In case of polysaccharides, a P1-9 derived Rha-Man polysaccharide and $A$. faecalis-derived curdlan were found to induce the full transformation in a dose-response fashion with curdlan being the more active derivative. Intriguingly, combinations of phospholipids and curdlan induced the full morphogenic transition at rates exceeding in part the sum of single compound contributions and resulting in the complete transformation of almost all larvae within $24 \mathrm{~h}$. Although, only representative derivatives of both bacterial compound classes were investigated in this study, the results are of crucial importance for future research directions in all facets for the following reasons:

34 Firstly, the structure, concentration and combination-dependency of the morphogenic response hints towards species-specific cross-kingdom interactions that might allow for the optimal habitat selection, despite the general global abundance of both compound classes in the bacterial world. ${ }^{36-38}$ Here, it can be speculated that only specific bacterial biofilm compositions, which induce the full transformation within less than $24 \mathrm{~h}$, presumably enhance the likelihood of survival of the individual larvae in highly competitive environments. Thus, our study will guide future 
1 investigations into the beneficial microbiome and the long-term survival of naturally-induced

2 Hydractinia colonies.

3 Secondly, our studies pave the way to examine additive and synergistic behavior of different

4 bacterial signals that trigger animal signaling systems. Only few studies have so far focused on

5 synergistic effects of morphogens in the marine environment, ${ }^{4-7}$ which includes studies on

6 sulfonolipids (RIFs) and LPEs, that in combination induce the formation of predatory rosette-like

7 stage of the choanoflagellate S. rosetta, ${ }^{39-41}$ and the recent identification of synergistically acting

8 nucleobases from marine bacteria, that induce metamorphosis of the invasive fouling mussel

9 Mytilopsis sallei. ${ }^{42}$ However, detailed mechanistic studies about mode of perception and

10 synergism in most model systems are thoroughly missing.

11 Thirdly, the identification of a novel polysaccharide and the detection of other morphogenic, yet

12 uncharacterized derivatives, encourages research directed towards the elucidation of their

13 biosynthetic pathways and regulation and might enable their future structure elucidation and

14 biosynthetic engineering. ${ }^{43-45}$

15 Fourthly, for Hydractinia it has been proposed from early on that neurosensory cells dominantly

16 located at or near the anterior pole and in part on its tapered posterior tip are responsible for the

17 detection of the bacterial cues. ${ }^{19,20}$ Upon physical contact with lipid-rich vesicles and cell

18 fragments naturally present within marine biofilms, phospholipids could passively integrate into

19 the Hydractinia membrane; a hypothesis that is supported by our findings that fluorescence-

20 labeled phospholipids are quickly integrated into membranes of Hydractinia larvae. Once

21 integrated, specific phospholipids could act as ligands for certain receptors or induce changes in

22 membrane fluidity resulting in the recruitment of, e.g., PKC involved in cellular signaling

23 processes. ${ }^{46-48}$ In addition, LPAs have been recognized as potent mitogen in humans since

24 decades due to their interactions with G-protein-coupled receptors (GPCRs), thereby altering

25 many different cellular responses in humans, such as proliferation, survival, cytoskeletal changes

26 or calcium influx. ${ }^{49}$ Thus, a homologous mode of action could be hypothesized for Hydractinia. In

27 contrast, morphogenic EPS molecules presumably require detection via dedicated receptors as

28 described for EPS-mediated host-pathogen interactions. ${ }^{50,51}$ In particular curdlan has been

29 previously reported to act on lectin-type receptors in humans; a receptor-type, which have also

30 been detected in a Hydractinia transcriptome study. ${ }^{52}$

31 In summary, the results of our studies will allow us to establish Hydractinia as a model system to

32 investigate more closely host-microbe interactions and will guide future research on molecule-

33 receptor interactions. Our results also open several avenues for future studies on other aspects of

34 how bacterial signals trigger animal development in the marine world, which could have potential

35 practical applications for preventing biofouling, coral reef management and aquaculture

36 husbandry. 


\section{Materials and Methods}

2 Supplementary Information (SI) available: details on fermentation, cultivation, bioassays, isolation

3 procedures, ESI-HRMS, ${ }^{1} \mathrm{H}$ NMR, ${ }^{13} \mathrm{C}$ NMR, and $2 \mathrm{D}$ NMR spectra as well as additional assay

4 data.

\section{Acknowledgments}

7 We are grateful for financial support from the German Research Foundation (DFG, CRC1127

8 ChemBioSys, BE 4799/2-1). CB greatly acknowledges funding by the ERC (ERC Grant number:

9 802736, MORPHEUS). MR is generously supported by the Jena School for Microbial

10 Communication (JSMC, DFG). Mrs. Heike Heinecke (HKI) for recording NMR spectra, Mrs.

11 Andrea Perner (HKI) for HRMS measurements, Toni Neuwirth for GC-MS measurements and

12 Johan Kufs for assisting in fluorescence imaging. We also would like to thank Prof. Valerie Paul

13 for the generous supply of Pseudoaltermonas sp. P5, and Theresa Jautzus for critical comments

14 on the manuscript. We are very grateful for the support by the Alfred-Wegner Sylt team and Ms

15 Birgit Hussel for their hospitality during field work.

16

Conflict of interest statement

The authors declare no conflict of interest. 


\section{References}

1. M.-G. Hadfield, V.-J. Paul, "Natural chemical cues for settlement and metamorphosis of marine invertebrate larvae" in Marine Chemical Ecology, J.-B. McClintock, B.-J. Baker, Eds. (CRC Press LLC, 2001), pp. 431-461.

2. C.-E. Zobell, E.-C. Allen, The Significance of Marine Bacteria in the Fouling of Submerged Surfaces. J. Bacteriol. 29, 239-251 (1935).

3. A.-M. Cantley, J. Clardy, Animals in a bacterial world: opportunities for chemical ecology. Nat. Prod. Rep. 32, 888-892 (2015).

4. T. Wichard, C. Beemelmanns, Role of chemical mediators in aquatic interactions across the prokaryote eukaryote boundary. J. Chem. Ecol. 44, 1008-1021 (2018).

5. M.-G. Hadfield, Biofilms and marine invertebrate larvae: what bacteria produce that larvae use to choose settlement sites. Annu. Rev. Mar. Sci. 3, 453-470 (2011).

6. A. Woznica, N. King, Lessons from simple marine models on the bacterial regulation of eukaryotic development. Curr. Opin. Microbiol. 43, 108-116 (2018).

7. M. McFall-Ngai, M.-G. Hadfield, T.-C. Bosch, H.-V. Carey, T. Domazet-Lošo, A.-E. Douglas, N. Dubilier, G. Eberl, T. Fukami, S.-F. Gilbert, U. Hentschel, N. King, S. Kjelleberg, A.-H. Knoll, N. Kremer, S.-K. Mazmanian, J.-L. Metcalf, K. Nealson, N.-E. Pierce, J.-F. Rawls, A. Reid, E.-G. Ruby, M. Rumpho, J.-G. Sanders, D. Tautz, J.-J. Wernegreen, Animals in a bacterial world, a new imperative for the life sciences. Proc. Natl. Acad. Sci. USA. 110, 3229-3236 (2013).

8. Y. Matsuo, H. Imagawa, M. Nishizawa, Y. Shizuri, Isolation of an algal morphogenesis inducer from a marine bacterium. Science. 307, 1598 (2005).

9. J.-D. Zardus, B.-T. Nedved, Y. Huang, C. Tran, M.-G. Hadfield, Microbial biofilms facilitate adhesion in biofouling invertebrates. Biol. Bull. 214, 91-98 (2008).

10. S. Dobretsov, R.-M. Abed, M. Teplitski, Inhibition of biofouling by marine microorganisms. Biofouling. 29, 423-441 (2013).

11. J.-M. Sneed, K.-H. Sharp, K.-B. Ritchie, V.-J. Paul, The chemical cue tetrabromopyrrole from a biofilm bacterium induces settlement of multiple Caribbean corals. Proc Biol Sci. 281, 20133086 (2014).

12. J. Tebben, D.-M. Tapiolas, C.-A. Motti, D. Abrego, A.-P. Negri, L.-L. Blackall, P.-D. Steinberg, T. Harder, Induction of larval metamorphosis of the coral Acropora millepora by tetrabromopyrrole isolated from a Pseudoalteromonas bacterium. PLoS One. 29, 6, e19082 (2011).

13. N.-J. Shikuma, M. Pilhofer, G.-L. Weiss, M.-G. Hadfield, G.-J. Jensen, D.-K. Newman, Marine tubeworm metamorphosis induced by arrays of bacterial phage tail-like structures. Science 343, 529-533 (2014).

14. N.-J. Shikuma, I. Antoshechkin, J.-M. Medeiros, M. Pilhofer, D.-K. Newman, Stepwise metamorphosis of the tubeworm Hydroides elegans is mediated by a bacterial inducer and MAPK signaling. Proc Natl Acad Sci U S A. 113, 10097-10102 (2016).

15. C.-F. Ericson, F. Eisenstein, J.-M.Medeiros, K.-E. Malter, G.-S. Cavalcanti, R.-W. Zeller, D.-K. Newman, M. Pilhofer, N.-J. Shikuma, A contractile injection system stimulates tubeworm metamorphosis by translocating a proteinaceous effector. eLife. 8, e46845 (2019).

16. M. L Freckelton, B. T. Nedved, Y-S. Cai, S. Cao, H. Turano, R. A. Alegado, M. G. Hadfield; bioRxiv preprint first posted online Nov. 29, 2019; doi: http://dx.doi.org/10.1101/851519

17. M.-L. Freckelton, B.-T. Nedved, M.-G. Hadfield, (2017). Induction of invertebrate larval settlement; different bacteria, different mechanisms? Sci. Rep. 7, 42557 (2017).

18. T. Leitz, T. Wagner, The marine bacterium Alteromonas espejiana induces metamorphosis of the hydroid Hydractinia echinata. Mar. Biol. 115, 173-178 (1993).

19. S. Seipp, J. Schmich, T. Kehrwald, T. Leitz, Metamorphosis of Hydractinia echinatanatural versus artificial induction and developmental plasticity. Dev. Genes. Evol. 217, 385-394 (2007). 
20. U. Technau, R.-E. Steele, Evolutionary crossroads in developmental biology: Cnidaria. Development, 138, 1447-1458 (2011).

21. M. Steven, Sanders, Z. Ma, J. M. Hughes, B. M. Riscoe, G. A. Gibson, A. M. Watson, H. Flici, U. Frank, C. E. Schnitzler, A. D. Baxevanis, M. L. Nicotra, CRISPR/Cas9-mediated gene knocking in the hydroid Hydractinia symbiolongicarpus. BMC Genomics. 19, 649 (2018).

22. M. Kroiher, S. Berking, On natural metamorphosis inducers of the cnidarians Hydractinia echinata (Hydrozoa) and Aurelia aurita (Scyphozoa). Helgol. Mar. Res. 53, 118-121 (1999).

23. T. Schneider, T. Leitz, Protein kinase $C$ in hydrozoans: involvement in metamorphosis of Hydractinia and in pattern formation of Hydra. Roux's arch. dev. biol., 203, 422-428 (1994).

24. H. Guo, M. Rischer, M. Sperfeld, C. Weigel, K.-D. Menzel, J. Clardy, C. Beemelmanns, Natural products and morphogenic activity of $y$-Proteobacteria associated with the marine hydroid polyp Hydractinia echinata. Bioorg. Med. Chem. 25, 6088-6097 (2017).

25. J.-L. Klassen, T. Wolf, M. Rischer, H. Guo, E. Shelest, J. Clardy, C. Beemelmanns, Draft Genome Sequences of Six Pseudoalteromonas sp. Strains P1-7a, P1-9, P1-13-1a, P116-1b, P1-25 and P1-26, which Induce Larval Settlement and Metamorphosis in Hydractinia echinata. Genome Announc. 3, e01477-15 (2015).

26. M. Rischer, J.-L. Klassen, T. Wolf, H. Guo, E. Shelest, J. Clardy, C. Beemelmanns,Draft Genome Sequence of Shewanella sp. P1-14-1, a Bacterial Inducer of Settlement and Morphogenesis in Larvae of the Marine Hydroid Hydractinia Echinata. Genome Announc 4(1), e00003-16 (2016).

27. J.-L. Klassen, M. Rischer, T. Wolf, H. Guo, E. Shelest, J. Clardy, C. Beemelmanns, Genome Sequences of Three Pseudoalteromonas Strains P1-8, P1-11 and P1-30 Isolated from the Marine Hydroid Hydractinia echinata. Genome Announc. 3, e01380-15 (2015).

28. M. Wang, J. J. Carver, V. V. Phelan, L. M. Sanchez, N. Garg, Y. Peng, D. D. Nguyen et al. "Sharing and community curation of mass spectrometry data with Global Natural Products Social Molecular Networking." Nature Biotechnology 34, 8, 828 (2016).

29. H. Sunshine, M. L. Iruela-Arispe, Membrane lipids and cell signaling, Curr. Opin. Lipidol. 28, 408-413 (2017)

30. L. Zheng, Y. Lin, S. Lu, J. Zhang, M. Bogdanov, Biogenesis, Transport and Remodeling of Lysophospholipids in Gram-negative Bacteria. Biochim. Biophys. Acta. Mol. Cell. Biol. Lipids. 862, 1404-1413 (2017).

31. K. Makide, H. Kitamura, Y. Sato, M. Okutani, J. Aoki, Emerging lysophospholipid mediators, lysophosphatidylserine, lysophosphatidylthreonine, lysophosphatidylethanolamine and lysophosphatidylglycerol. Prostag. Oth. Lipid M. 89, 135-139 (2009).

32. R. Zhang, K. J. Edgar, Properties, chemistry, and applications of the bioactive polysaccharide curdlan, Biomacromolecules 15, 1079-1096 (2014)

33. G. Raposo, W. Stoorvogel, Extracellular vesicles: exosomes, microvesicles, and friends. J. Cell Biol. 200, 373-383 (2013).

34. S.-J. Biller, F. Schubotz, S.-E. Roggensack, A.-W. Thompson R.-E. Summons, S.-W. Crisholm, Bacterial vesicles in marine ecosystems. Science. 343, 183-186 (2014).

35. J. Lynch, R.-A. Alegado, Spheres of hope, orbs of doom: the good and bad of outer membrane vesicles in interspecies dynamics, J. Bacteril. 199, e00012-17 (2017).

36. E. Maunders, M. Welch, Matrix exopolysaccharides; the sticky side of biofilm formation. FEMS Microbiol. Lett. 364, fnx120 (2017).

37. M.-B. Lilledahl, B.-T. Stokke, Novel imaging technologies for characterization of microbial extracellular polysaccharides. Front. Microbiol. 6, 525 (2015).

38. D. Parkar, R. Jadhav, M. Pimpliskar, Marine bacterial extracellular polysaccharides. J. Coast. Life. Med. 5, 29-35 (2007). 
39. R.-A. Alegado, L.-W. Brown, S. Cao, R.-K. Dermenjian, R. Zuzow, S.-R. Fairclough, J. Clardy, N. King, A bacterial sulfonolipid triggers multicellular development in the closest living relatives of animals. eLife. 1, e00013 (2012).

40. C. Beemelmanns, A. Woznica, R.-A. Alegado, A.-M. Cantley, N. King, J. Clardy, Synthesis of the rosette-inducing factor RIF-1 and analogs. J. Am. Chem. Soc. 136, 10210-10213 (2014).

41. A. Woznica, A.-M. Cantley, C. Beemelmanns, E. Freinkman, J. Clardy, N. King, Bacterial lipids activate, synergize, and inhibit a developmental switch in choanoflagellates. Proc. Natl. Acad. Sci. U S A. 12, 113, 7894-7899 (2016).

42. J. He, Q. Dai, Y. Qi, P. Su, M. Huang, C. Ke, D. Feng, Bacterial nucleobases synergistically induce larval settlement and metamorphosis in the invasive mussel Mytilopsis sallei. Appl. Environ. Microbiol. doi:10.1128/AEM.01039-19 (2019).

43. N.-A. Komandrova, M.-S. Kokoulin, A.-I. Kalinovskiy, S.-V. Tomshich, L.-A. Romanenko, V.-E. Vaskovsky, The O-specific polysaccharide from the marine bacterium Pseudoalteromonas agarivorans KMM 255T. Carbohydrate research, Carbohydr. Res. 414, 60-4 (2015).

44. D.-H. Limoli, C.-J. Jones, D.-J.Wozniak, Bacterial extracellular polysaccharides in biofilm formation and function. Microbiol. Spectr. 3 (2014).

45. A. Casillo, R. Lanzetta, M. Parrilli, M. M. Corsaro, Exopolysaccharides from Marine and Marine Extremophilic Bacteria: Structures, Properties, Ecological Roles and Applications. Mar. Drugs 16, E69 (2018)

46. Y.-C. Yung, N.-C. Stoddard, H. Mirendil, J. Chun, Lysophosphatidic Acid signaling in the nervous system. Neuron. 85, 669-682 (2015).

47. G. Amador-Cano, E. Carpizo-Ituarte, D. Cristino-Jorge D, Role of protein kinase C, Gprotein coupled receptors, and calcium flux during metamorphosis of the sea urchin Strongylocentrotus purpuratus. Biol Bull. 210, 121-131 (2006).

48. G. Henningi, D.-K. Hofmann, Y.-B. Yahu, Metamorphic processes in the soft corals Heteroxenia fuscescens and Xenia umbellata: The effect of protein kinase $\mathrm{C}$ activators and inhibitors. Invertebr. Reprod. Dev. 34, 35-45 (1998).

49. M.-E. Lin, D. R. Herr, J. Chun, Lysophosphatidic acid (LPA) receptors: signaling properties and disease relevance. Prostaglandins Other Lipid Mediat. 91, 130-138 (2010).

50. P. Albersheim, A.-G. Darvill, M. McNeil, B.-S. Valent, J.-K. Sharp, E.-A. Nothnagel, K.-R. Davis, "Oligosaccharins: Naturally occurring carbohydrates with biological regulatory functions", in Structure and Function of Plant Genomes, O. Ciferri, L. Durell, Eds (Springer, 1983), pp. 293-312.

51. U. Szewzyk, C. Holmström, M. Wrangstadh, Relevance of the exopolysaccharide of marine Pseudomonas sp. S9 for the attachment of Ciona intestinalis larvae. Ecol. Progress. Ser. 259-265 (1991).

52. J. Soza-Ried, A. Hotz-Wagenblatt, K.-H. Glatting, C. del Val, K. Fellenberg, H. R. Bode, U. Frank, J. D. Hoheisel, M. Frohme, The transcriptome of the colonial marine hydroid Hydractinia echinata. FEBS J 277, 197-209 (2009). 